\title{
Corneal organ culture: effects of serum and a stabilised form of L-glutamine
}

\author{
M G Ayoubi, W J Armitage, D L Easty
}

\begin{abstract}
Aim-Organ culture medium for corneas contains labile components, such as L-glutamine, whose loss could be a limiting factor to the length of storage. The medium is also supplemented with fetal bovine serum (FBS), which can vary significantly between different batches. The aim of this study was to establish the need for FBS during corneal organ culture, and to determine whether substitution of $L$-glutamine by the stable dipeptide L-analyl-L-glutamine was beneficial.

Methods-Porcine corneoscleral discs were suspended in $80 \mathrm{ml}$ of organ culture medium (HEPES buffered Eagle's MEM with Earle's salts, 26 mmoll $\mathrm{NaHCO}_{3}$, penicillin, streptomycin, and amphotericin B) and kept at $34^{\circ} \mathrm{C}$. The medium contained either $2 \mathrm{mmol} / \mathrm{l}$-glutamine or 2 mmol/1 L-analyl-L-glutamine, and was either serum free or contained $2 \%$ FBS. At weekly intervals, five corneas from each group were stained with trypan blue and alizarin red $S$, and the surface area and shape of 100 endothelial cells were determined for each cornea.
\end{abstract}

Results-No differences were observed between corneas in organ culture medium with L-glutamine or L-analyl-L-glutamine. In serum free medium, endothelial cell density remained constant for the first week, but then declined rapidly over the next 2 weeks. With $2 \%$ FBS, there was no loss of endothelial cells for the first 2 weeks, but cell density had halved by the fourth week of organ culture.

Conclusion-The presence of $2 \%$ FBS extended the period of endothelial stability, but no advantage was gained from the stabilised form of L-glutamine. The overall loss of endothelial cells was much greater than would be expected for human corneas.

(Br F Ophthalmol 1996;80:740-744)

Organ culture was first introduced as a technique for storing corneas in the $1970 \mathrm{~s}^{1{ }^{2}}$ Since then, many thousands of corneas stored by this method for periods of up to 1 month have been transplanted successfully. Although little used in the USA, where the eye banks predominantly use hypothermic storage methods, many of the major European eye banks use organ culture as their method of choice and it has been used in the UK since $1986 .^{3}$ The advantages of organ culture include scheduling of routine corneal grafts, ready availability of tissue for emergency grafts, reduced wastage of tissue, greater scope for tissue matching where appropriate, reduced risk of bacterial and fungal contamination of the donor cornea, and routine assessment of endothelial quality immediately before surgical use of the tissue.

The organ culture medium used in Bristol is based on HEPES buffered Eagle's minimum essential medium (MEM) with Earle's salts, and contains $2 \%$ fetal bovine serum (FBS), 26 $\mathrm{mmol} / \mathrm{l}$ sodium bicarbonate, $2 \mathrm{mmol} / 1$ L-glutamine, antibiotics (penicillin and streptomycin), and an antimycotic (amphotericin B). ${ }^{4}$ During organ culture, as in any tissue culture system, the composition of the medium undoubtedly changes with time as a result of cellular metabolic activity: substrates are utilised, labile components are lost, and waste metabolic products are released from cells. In routine tissue culture, a stable environment is maintained for the cells by changing the medium, typically every few days, and some eye banks accordingly do change their organ culture medium every 7-14 days. But we, and others, do not follow this practice: once the corneas have been placed into culture the medium is not changed. This is felt to be justified because the rate of substrate utilisation is likely to be lower in corneal organ culture, where the intention is merely cell maintenance, than in cultures of proliferating cells. In addition, a reserve of substrates is provided by the relatively large volume $(80 \mathrm{ml})$ of medium used for organ culture, which would also help to dilute metabolites, such as lactate, that could adversely affect the culture environment.

It is clear from the clinical results of grafts carried out with organ cultured human corneas that the endothelium can survive under these conditions for several weeks. ${ }^{5-7}$ In our experience in the Bristol Eye Bank, however, the proportion of corneas unsuitable for transplantation increases with storage time from less than $20 \%$ after 2 weeks to over $40 \%$ after more than 4 weeks of organ culture. This suggests either a 
fundamental deficiency of the medium (that is, the medium lacks specific components required for the maintenance of corneal endothelial cells) or that progressive changes in the medium are indeed having an adverse effect.

One aim of this study, therefore, was to determine whether loss of the labile amino acid, L-glutamine, which in some cell types is important for cellular metabolism, ${ }^{8}$ was in part responsible for this endothelial decline. Stabilised forms of L-glutamine are available, such as the dipeptide, L-analyl-L-glutamine, that can be utilised by cells. Substitution of L-glutamine in the culture medium by the dipeptide should, therefore, ensure a source of glutamine for the corneal endothelium throughout the period of organ culture.

We also wished to determine whether serum was required for maintenance of corneal endothelium during organ culture. Serum contains many components required by cells for growth and maintenance, such as proteins, lipids, hormones, growth factors, and inorganic trace elements, but there are some notable disadvantages to its use-namely, its cost, significant variations between different batches of serum, and concern that foreign protein may be adsorbed onto the corneal surface. To our knowledge, however, there has never been any specific indication that the use of fetal bovine serum has actually resulted in any adverse clinical consequences, yet a serum free medium for corneal organ culture is certainly considered to be a desirable goal.

\section{Methods}

PREPARATION OF CORNEAS

Porcine eyes were obtained from a local abattoir. Extraneous tissue was removed from the surface of the eyes, which were then rinsed thoroughly in de-ionised water. They were then cleaned using the same protocol followed in the Bristol Eye Bank. They were first rinsed in four washes of sterile saline and then immersed in $1 \%$ polyvinylpyrrolidone-iodine (PVP-I) for 2 minutes. The iodine was neutralised by $0.1 \%$ sodium thiosulphate ( 1 minute), followed by a further rinse in sterile saline.

Corneas were excised with a 3-4 $\mathrm{mm}$ rim of sclera and suspended by a length of 5/0 Mersilk suture (Ethicon Ltd) in $80 \mathrm{ml}$ of tissue culture medium in $100 \mathrm{ml}$ glass DIN 58365/5 infusion bottles. The bottles were closed with silicone rubber stoppers. The cleaning of eyes and excision of corneoscleral discs were carried out in a laminar flow hood.

\section{ENDOTHELIAL ASSESSMENT}

Corneal endothelium was stained with trypan blue to detect cells that had lost membrane integrity, and with alizarin red $S$ to show endothelial cell borders. The method described by Taylor and Hunt ${ }^{9}$ was followed, ensuring that the $\mathrm{pH}$ of the alizarin red $\mathrm{S}$ solution was adjusted to 4.2 to maximise the dye lake reaction of this anthraquinone dye at the intercellular borders. After staining, corneas were fixed briefly by immersion in $2.5 \%$ glutaraldehyde solution in $0.15 \mathrm{~mol} / 1 \mathrm{cacody}-$ late buffer ( $\mathrm{pH} 7.2$ ) containing $3 \mathrm{mmol} / \mathrm{l} \mathrm{CaCl}_{2}$ for 10 minutes.

After staining and partial fixation, cell area $\left(\mu \mathrm{m}^{2}\right)$ and shape (number of cell sides) were determined for 100 cells on each cornea by light microscopy and image analysis (Leica Quantimet 500).

PROTOCOL

The basic organ culture medium comprised Eagle's minimum essential medium (MEM) with Earle's salts, $25 \mathrm{mmol} / \mathrm{l}$ HEPES buffer, and $26 \mathrm{mmol} / 1 \mathrm{NaHCO}_{3}$ (Gibco 32360), to which was added $100 \mathrm{U} / \mathrm{ml}$ penicillin, 0.1 $\mathrm{mg} / \mathrm{ml}$ streptomycin, and $0.25 \mu \mathrm{g} / \mathrm{ml}$ amphotericin B (Antibiotic/antimycotic solution, Sigma A4668). Fetal bovine serum (FBS, screened for mycoplasma), L-glutamine and Glutamax I were obtained from Gibco. Glutamax I is the dipeptide L-analyl-Lglutamine and is a stabilised form of L-glutamine. The serum was heat inactivated at $56^{\circ} \mathrm{C}$ for 30 minutes.

Corneas that were stained and fixed immediately after excision of the corneoscleral disc served as untreated controls. There were, in addition, four experimental groups defined by the supplements added to the basic organ culture medium: (1) basic medium with $2 \mathrm{mmol} / 1$ L-glutamine but no FBS; (2) basic medium with $2 \mathrm{mmol} / \mathrm{l}$ Glutamax but no FBS; (3) basic medium with $2 \mathrm{mmol} / 1 \mathrm{~L}$-glutamine and $2 \%$ FBS; and (4) basic medium with $2 \mathrm{mmol} / \mathrm{l}$ Glutamax and 2\% FBS.

The same organ culture medium used for each of these groups was also prepared with $5 \%$ dextran T500 (average molecular weight $500 \mathrm{kDa}$, Pharmacia 17-0320-02). This was needed to reverse the marked stromal oedema that occurred during organ culture of porcine corneas, and thus to thin the corneas before assessment of the endothelium.

Each group comprised 20 corneas, and every week for 4 weeks, five corneas from each group were placed into organ culture medium containing $5 \%$ dextran. After a further 24 hours in organ culture, the corneas were stained and endothelium assessed.

\section{STATISTICAL ANALYSIS}

Normal probability plots showed endothelial cell surface area to be normally distributed, and mean cell area $\left(\mu \mathrm{m}^{2}\right)$ was therefore determined for each cornea from 100 endothelial cells. The effects of the different culture media and time in organ culture on cell area were compared by one and two way analyses of variance (ANOVA). Unplanned comparisons subsequent to ANOVA were made, where appropriate, by Tukey's method. ${ }^{10}$ The cell density (cells $/ \mathrm{mm}^{2}$ ) of each cornea was estimated from $1 \times 10^{6} /$ mean cell area $\left(\mu \mathrm{m}^{2}\right)$. Changes in cell shape were analysed by $\chi^{2}$ tests. The level of significance for all statistical tests was set at $5 \%$. 


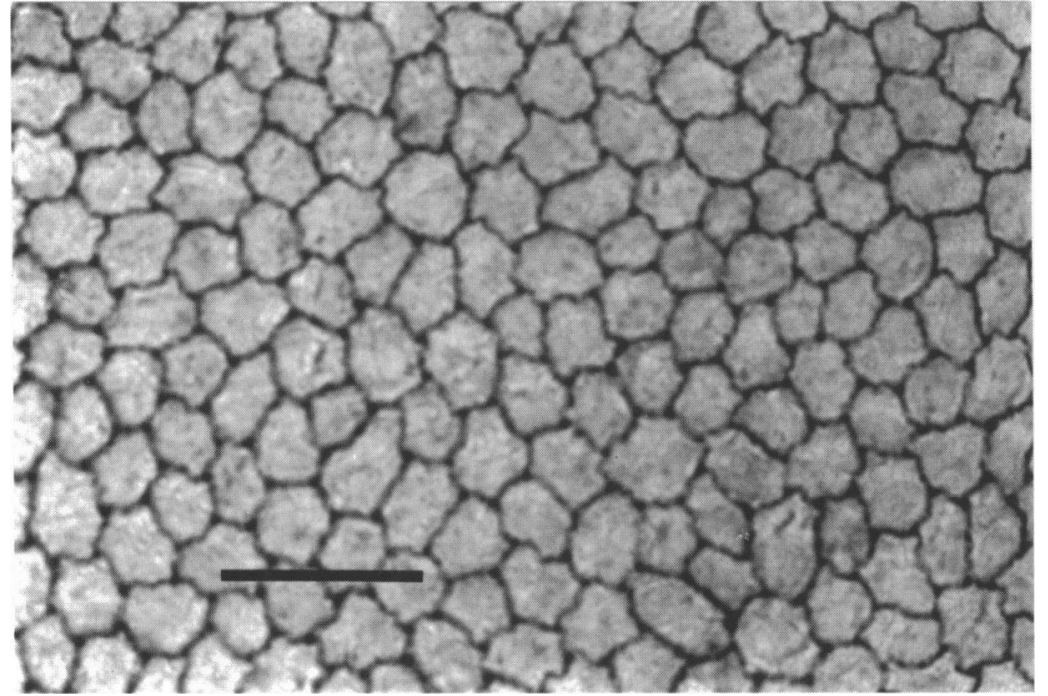

Figure 1 Endothelial mosaic stained with trypan blue and alizarin red $S$ of an untreated cornea that was not placed into organ culture. Bar $=50 \mu \mathrm{m}$.

\section{Results}

UNTREATED CONTROLS

The endothelium of corneas that had not been organ cultured formed a typically regular mosaic (Fig 1) with $56.4 \%$ of cells having a hexagonal shape. Mean cell area within this group of 10 corneas ranged from $248.3 \mu \mathrm{m}^{2}$
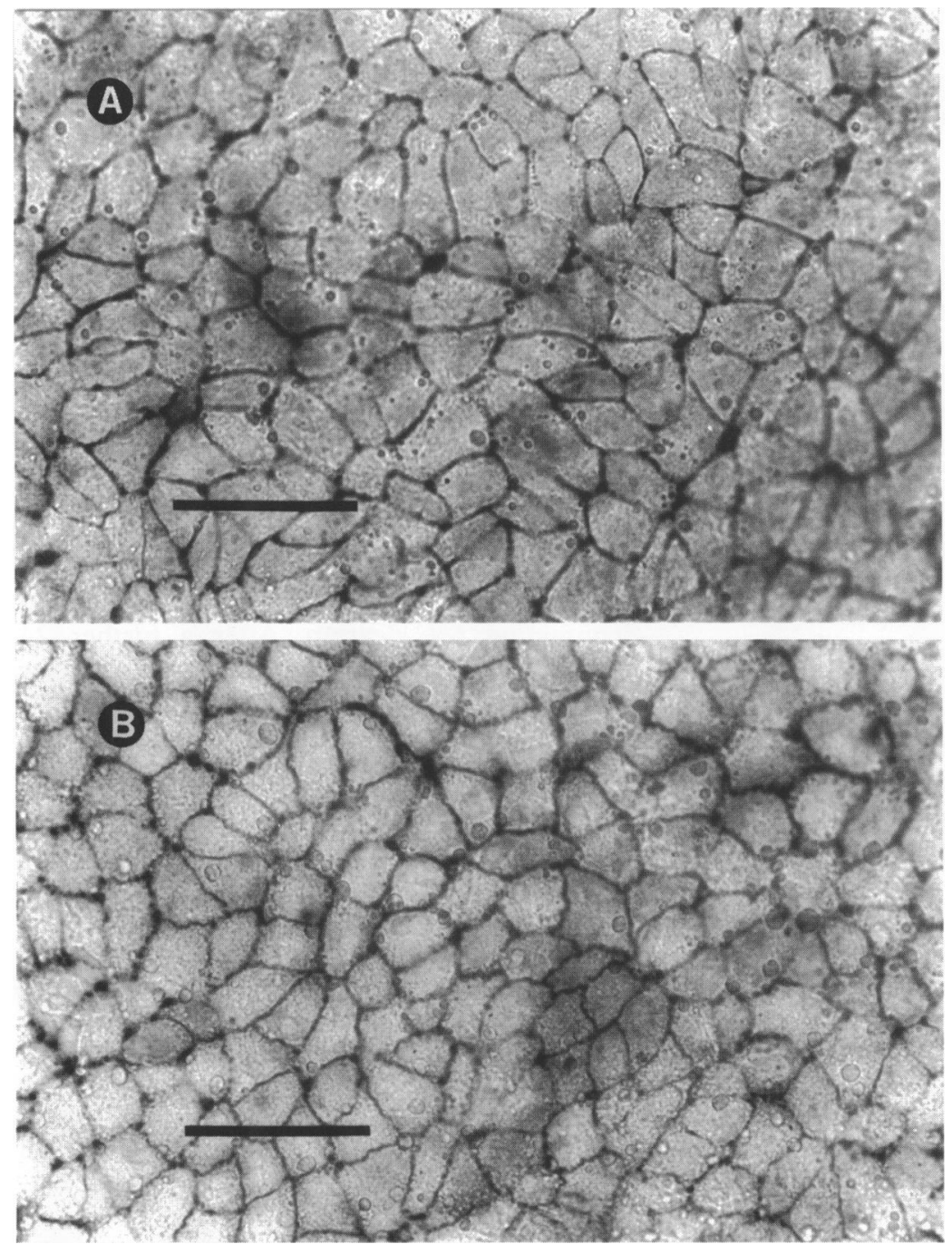

Figure 3 Corneal endothelium stained with trypan blue and alizarin red $S$ after 2 weeks in organ culture medium containing Glutamax. (A) Medium without FBS, (B) medium containing $2 \%$ FBS. Bar $=50 \mu \mathrm{m}$.

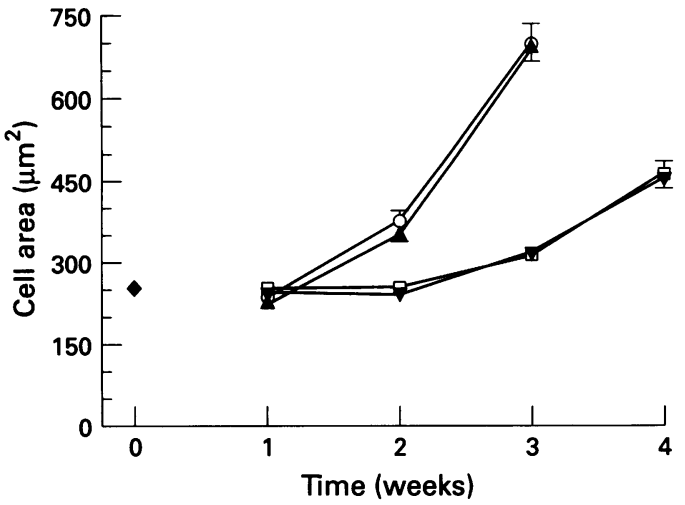

Figure 2 Change in endothelial cell area $\left(\mu m^{2}\right)$ during organ culture. Each point represents the mean cell area (SD) of five corneas: control $(\diamond)$; L-glutamine, no FBS (O); Glutamax, no FBS (A); L-glutamine with $2 \%$ FBS D); Glutamax with 2\% FBS (口).

(SD 48.5, CV 19.5\%, $\mathrm{n}=100$ cells) to 261.4 $\mu^{2}$ (SD 48.3, CV 18.5\%, $\mathrm{n}=100$ cells) Endothelial cell density, calculated for each cornea from the mean cell area, was 3936 cells/ $\mathrm{mm}^{2}$ (SD $63, \mathrm{n}=10$ corneas).

\section{CULTURE MEDIUM WITHOUT FBS}

In the absence of serum, there were marked changes in endothelial cell area with time in organ culture $(p<0.0001)$, but no differences were observed between corneas in medium containing L-glutamine or those in Glutamax medium $(p=0.109)$. There were no changes in cell area during the first week of organ culture ( $p>0.05$ versus control), but there was subsequently a rapid increase in cell area, indicating loss of endothelial cells, over the next 2 weeks (Figs 2, 3A, and 4A). After 4 weeks in culture, there was almost a complete absence of endothelium.

Changes in cell shape were also evident during organ culture and, as with cell area, there were no differences between the Glutamax and L-glutamine media (Figs 5A and 5B). Even within the first week, there was a significant shift towards cells with fewer sides $(p<0.001)$. After 2 weeks in organ culture, the proportions of hexagonal cells had fallen to $25 \%$ in L-glutamine medium and $20 \%$ in Glutamax medium.

CULTURE MEDIUM WITH $2 \%$ FBS

Endothelial cell area remained unchanged for 2 weeks in the presence of $2 \%$ FBS ( $>0.05$ versus control); but cell area had approximately doubled by the fourth week of organ culture (Fig 2). As with corneas organ cultured in the absence of serum, this increase in cell area due to loss of cells was not ameliorated by the presence of Glutamax $(p<0.09$ versus L-glutamine).

The appearance of the endothelium after 2 and 3 weeks of organ culture can be seen in Figures $3 B$ and $4 B$, respectively. There was a significant change in cell shape after only one week in organ culture $(p<0.001)$, and this became more marked with time (Figs $6 \mathrm{~A}$ and 6B). After 4 weeks, the proportions of hexagonal cells were only $15 \%$ in L-glutamine medium and $16 \%$ in Glutamax medium. 

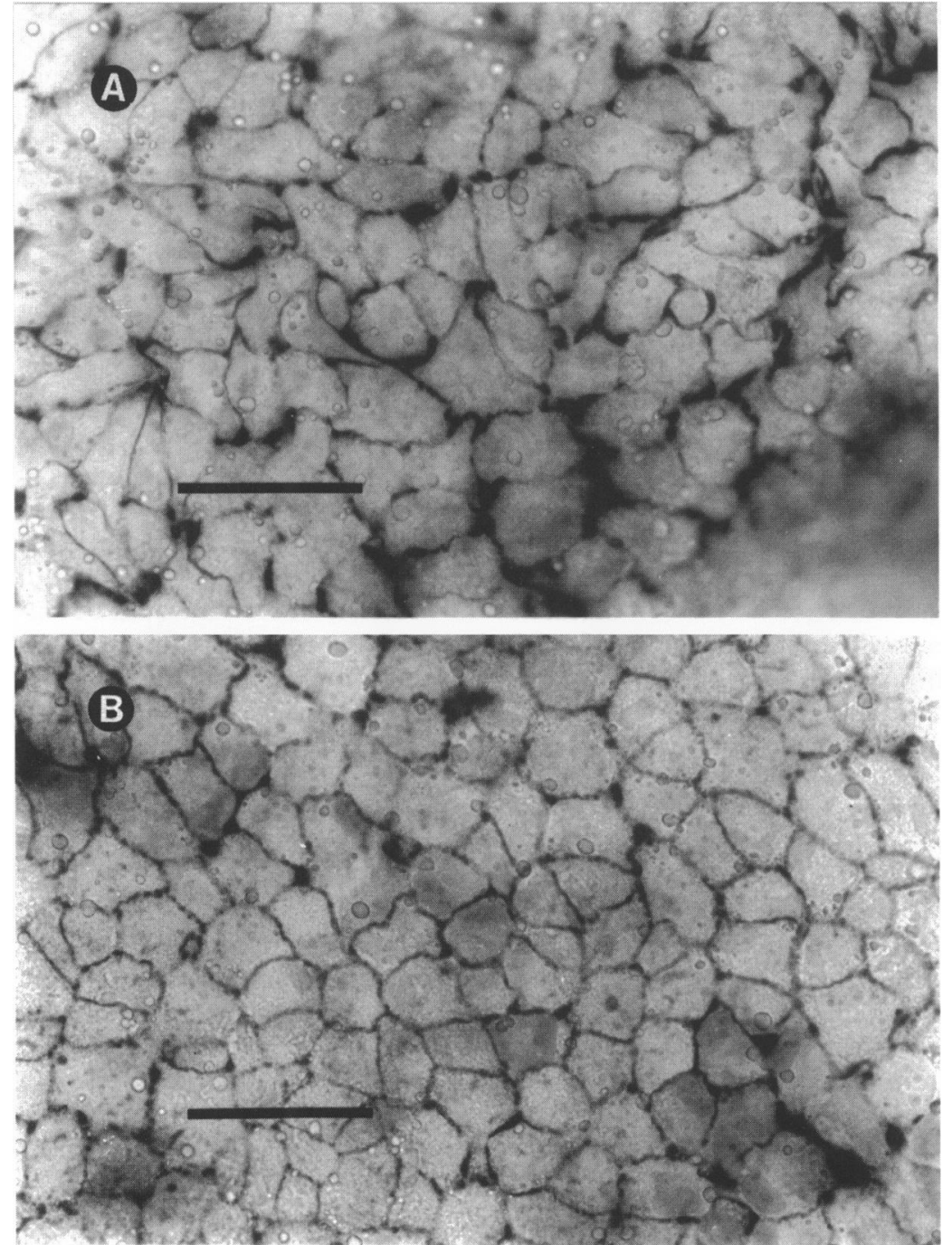

Figure 4 Corneal endothelium stained with trypan blue and alizarin red $S$ after 3 weeks in organ culture medium containing L-glutamine. (A) Medium without FBS, (B) medium containing $2 \%$ FBS. Bar $=50 \mu \mathrm{m}$.

\section{Discussion}

The practice of changing culture medium every few days is considered to be necessary for maintaining a stable environment for the growth of cells in vitro. Not only are depleted substrates and labile components replenished, but potentially harmful products of cellular metabolism are removed. The frequency of the change, the composition of the medium, and the requirements for supplements, such as serum, can vary markedly depending on the cell type and whether the cells are proliferating. ${ }^{11} \mathrm{~A}$ number of eye banks that use organ culture for storing human corneas, however, do not change the culture medium during the storage period, which may extend up to 4 weeks. In order to counter the loss of substrates utilised by the cells, the volume of medium used for organ culture of corneas tends to be relatively large, but the depletion of labile components, such as L-glutamine, will not be mitigated by this strategy.

Even though L-glutamine can be synthesised by cells from glutamic acid in an ATP dependent reaction catalysed by glutamine synthetase, it is considered to be a necessary supplement to tissue culture medium for many cell types. It has, however, been shown to degrade in culture medium (in the absence of
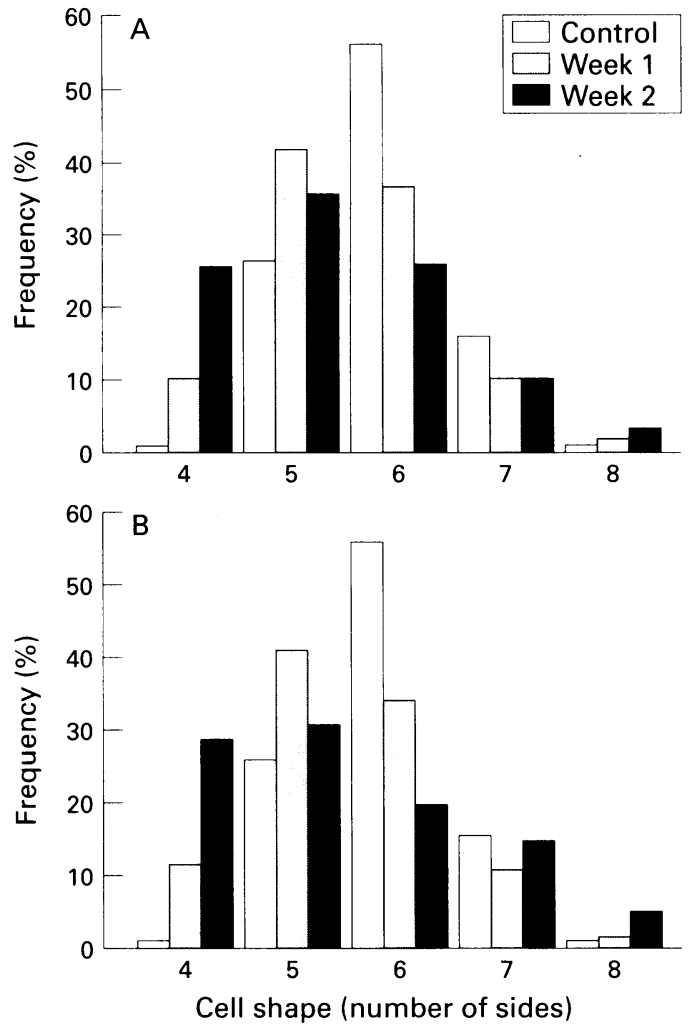

Figure 5 Change in distribution of endothelial cell shape of corneas organ cultured in medium without FBS. (A) Medium containing L-glutamine, (B) medium containing Glutamax.

cells) at a rate that is inversely related to temperature: at $35^{\circ} \mathrm{C}$, it has a half life of approximately 9 days (data from Sigma Chemical Company), which suggests that after 4 weeks its concentration in organ culture
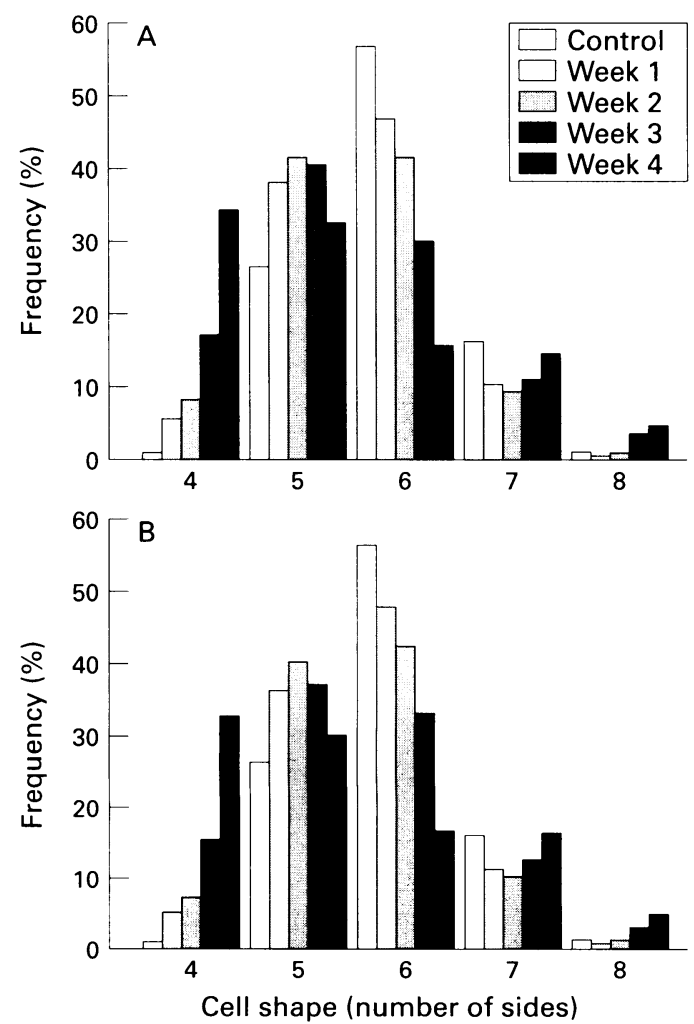

Figure 6 Change in distribution of endothelial cell shape of corneas organ cultured in medium containing $2 \% \mathrm{FBS}$. (A) Medium containing L-glutamine, (B) medium containing Glutamax. 
medium should have fallen by almost $90 \%$. Our results, however, could not demonstrate any advantage to substituting L-glutamine with the more stable peptide, L-analyl-L-glutamine.

The balance between glucose and glutamine as energy sources varies markedly between different cell types. ${ }^{8}{ }^{12}$ Cells also vary in their ability to adapt to glutamine-free media. ${ }^{13}$ For example, deprivation of glutamine leads to an increase in glutamine synthetase activity in both mouse fibroblasts (McCoy cells), which readily adapt to the absence of glutamine, and canine kidney epithelial cells (MDCK), which do not. But McCoy cells, unlike MDCK cells, also show a substantially increased rate of glutamate transport, which, coupled with the increased activity of glutamine synthetase, is likely to account for their tolerance of glutamine-free conditions.

There are perhaps three explanations for the apparent lack of benefit from using L-analyl-Lglutamine during organ culture of porcine cornea: firstly, glutamine may not be an important energy source for porcine corneal endothelial cells; secondly, these cells may adapt to and tolerate glutamine deprivation; and thirdly, other changes occurring in the medium may have masked any benefit derived from the continued presence of the stable form of glutamine. Apart from substrate depletion, there would also be a build up in the medium of potentially harmful metabolites such as lactate from glucose metabolism and, presumably, ammonia from glutamine metabolism. For example, Hjortdal, et al $^{14}$ reported that after 28 days of corneal organ culture, glucose concentration had fallen from 5.1 to $0.25 \mathrm{mmol} / 1$ and lactate concentration had risen from 2.5 to 11 $\mathrm{mmol} / 1$.

Although there appeared to be no benefit from using a stabilised form of glutamine during organ culture, there was a clear advantage gained from the presence of serum, albeit at a low concentration. It was notable, however, that even in the absence of serum, there was no loss of endothelial cells during the first week of organ culture, although the subsequent decline in endothelial cell density was rapid. With $2 \%$ FBS, cell density remained unchanged for 2 weeks, but then reduced by approximately $50 \%$ over the next 2 weeks. This loss of endothelial cells was much greater than would be expected for human corneas during organ culture-for example, a recent study reported endothelial cell loss of only $12 \%$ from human corneas after 3 weeks of organ culture. ${ }^{15}$ Despite the initial period of apparent stability in terms of cell density in the porcine corneas, changes in the distribution of cell shape were evident within 1 week, even in the presence of FBS.

The concentration of FBS (2\%) used for corneal organ culture is typical of that used in holding media for cell cultures that have reached confluence or where cell division is undesirable. ${ }^{11}$ The actual requirements of cor- neal endothelial cells for the trace elements, hormones, proteins, polypeptide growth factors, and other constituents of serum have not yet been established precisely. It is clear, however, that serum does contribute one or more components that do improve the maintenance of porcine corneal endothelium in organ culture.

In conclusion, no advantage was gained from using a stabilised form of glutamine during organ culture of porcine cornea, but a need for serum was established. The next step will be to determine whether serum can be effectively substituted by specific components, such as selenium, insulin, and transferrin, to allow corneal organ culture in a serum-free medium. The other main question is whether the decline in endothelial cells after 2 weeks of organ culture in the presence of serum would be significantly lessened by changing the medium. Any perceived gain in terms of reduced endothelial cell loss would have to be balanced against the disadvantages of having to change the organ culture medium several times. Each change of medium would carry the risk of bacterial or fungal contamination, which could render corneas unsuitable for transplantation. Moreover, such a practice would complicate a relatively straightforward storage method and lead to a substantial increase both in workload and expense in an eye bank such as Bristol, which has 150-200 corneas in organ culture at any one time.

1 Summerlin WT, Miller GE, Harris JE, Good RA. The organ-cultured cornea: an in vitro study. Invest Ophthalmol 1973;12:176-80.

2 Doughman DJ, Harris JE, Schmitt MK. Penetrating keratoplasty using $37^{\circ} \mathrm{C}$ organ cultured cornea. Trans Am Acad Ophthalmol Otolaryngol 1976:81:778-93.

3 Armitage WJ, Moss SJ, Easty DL, Bradley BA. Supply of corneal tissue in the United Kingdom. Br 7 Ophthalmol 1990;74:685-7.

4 Armitage WJ, Moss SJ. Storage of corneas for transplantation. In: Easty DL, ed. Current ophthalmic surgery. London tion. In: Easty DL, ed. Current

5 Vail A, Gore SM, Bradley BA, Easty DL, Rogers CA. Corneal graft survival and visual outcome: a multicenter study. Ophthalmology 1994:101:120-7.

6 Vail A, Gore SM, Bradley BA, Easty DL, Rogers CA Armitage WJ. Influence of donor and histocompatibility factors on corneal graft outcome. Transplantation 1994;58: 1210-7.

7 Redmond RM, Armitage WJ, Whittle J, Moss SJ, Easty DI Long term survival of endothelium following transplantation of corneas stored by organ culture. Br $\mathcal{F}$ Ophthalmol 1992;76:479-81.

8 Spolarics Z, Lang CH, Bagby GJ, Spitzer JJ. Glutamine and Spolarics Z, Lang CH, Bagby GJ, Spitzer JJ. Glutamine and fatty acid oxidation are the main sources of energy for Kupffer and

G185-90.
Taylor MJ, Hunt CJ. Dual staining of corneal endothelium with trypan blue and alizarin red S: importance of $\mathrm{pH}$ for the dye-lake reaction. $B r f$ Ophthalmol 1981;65:815-9.

10 Sokal RR, Rohlf FJ. Biometry. New York: WH Freeman \& Co, 1981 .

11 Freshney RI. Culture of animal cells: a manual of basic technique. New York: Wiley-Liss, 1987.

12 Wu G, Greene LW. Glutamine and glucose metabolism in bovine blood lymphocytes. Comp Biochem Physiol 1992; 103:821-5.

13 McDermott RH, Butler M. Uptake of glutamate, not glutamine synthetase, regulates adaptation of mammalian cells to glutamine-free medium. $\mathcal{F}$ Cell Sci 1993;104:51-8.

14 Hjortdal JO, Ehlers N, Andersen CU. Some metabolic changes during human corneal organ culture. Acta Ophthalmol 1989;67:295-300.

15 Borderie VM, Kantelip BM, Delbosc BY, Oppermann MT, Laroche L. Morphology, histology, and ultrastructure of human C31 organ-cultured corneas. Cornea 1995;14:30010. 